\title{
Quality Control Assessment for Chemical Analysis
}

\author{
Murad Alsawalha \\ Jubail Industrial College, Chemical and Process Engineering Technology, Jubail Industrial City 31961, Saudi Arabia
}

\begin{abstract}
The current research focused on the importance of quality control for chemical analysis through instrument calibration conditions, on different organochlorine pesticides samples using standard mixture solutions. For this aim statistical quality control calculations were performed to optimize the validation of Gas chromatography mass spectrometry (GC-MS) and its compatibility range. The obtained quality control assessment results confirmed instrument method's performance in term of the instrument accuracy, excellent sensitivity and selectivity of the consequences.
\end{abstract}

Keywords: Quality control, Chemical analysis, Lower detection limit.

\section{Introduction}

Quality has become a crucial demand in the social, economic, technical and scientific field. Despite the fact that the concept is as old as human activities, it has become a buzzword in the last few years. One of the important things that should consider during analysis is the calibration and that any calibration expression is adequate, important statistics-related questions must be asked. It should be noted that although all of the following questions are important, perhaps the most important (and often neglected) query is the last one regarding uncertainty [9].

1) Was the design of the calibration study appropriate?

2)Were the resulting data analyzed in a statistically sound manner?

(2a) Is the chosen model adequate?

(2b) Is the fitting technique appropriate?

(2c) How much bias does the curve reflect?

(2d) What is the uncertainty in any sample result that is estimated from the curve?

Therefore, it is important to choose the correct calibration model for each particular analyte even though this could prove to be time consuming, particularly when establishing a new method for over a hundred analysts [2], [3]. The unwise choice of a calibration model may give rise to inaccuracies as high as $100 \%$ for analytical determinations due to the presence of high random errors and bias [9]. Statistical calculations and distributions therefore, play a major role in performing validation in chemical measurements and analytical determinations as well as systematically determining the level of certainty reached by the analytical procedure [9].

Statistical designs are required to test whether the correct calibration design was chosen, whether the data fit the model precisely, identify outliers as well as determining the level of bias contributed on each analytical system, component or module of the measurement system(GC-MS). It is reasonable to expect that outliers will be present in analysis of matrix based extracts [4].

Generally,quality control assessment using GC Ms spectroscopy techniques on different organochlorine compounds is very important. The Organochlorine pesticides (OCPs) are a kind of widely used pesticides for the effective control of pests and diseases of plants and animals [1]. Due to its low biodegradability and high persistence in the natural environment, OCPs is ubiquitous among samples of air, water, soil, sediments, food, and biological tissues and has been shown to have potentially harmful effects on human beings.Some OCPs, includinghexachlorocyclohexanes (HCHs), dichlorodiphenyltrichloroethanes (DDTs), aldrin, dieldrin, endrin, chlordane, heptachlor, and hexachlorobenzene, are listed in the Stockholm Convention as persistent organic pollutants (POPs) and have been banned by the United Nations Environment Program (UNEP) for their link to reproductive disorders, disruption of the cellular immune system, cancer predisposition, and nervous system damage of humans [5]- [11].

\section{Experimental}

\subsection{Materials}

For this study, different types of organochlorine residues were considered for the quality control study as provided in Table 1 .

Table 1: Reference material for the organochlorine compounds

\begin{tabular}{|l|c|}
\hline Compound name & Purity (\%) \\
\hline HCH-alpha & 99.0 \\
\hline HCH-Beta & 99.0 \\
\hline HCH-gamma & 99.0 \\
\hline Heptachlor & 99.0 \\
\hline Aldrin & 98.0 \\
\hline Heptachlorepoxide & 98.0 \\
\hline 2,4 DDE & 99.0 \\
\hline Endsulphane - alpha & 98.0 \\
\hline di-aldrin & 98.0 \\
\hline 2,4 DDD & 99.0 \\
\hline Endrin & 98.0 \\
\hline Endsulphane-beta & 96.0 \\
\hline 4,4 DDD & 99.0 \\
\hline 2,4 DDT & 99.0 \\
\hline 4,4 DDT & 99.0 \\
\hline
\end{tabular}




\section{International Journal of Science and Research (IJSR) \\ ISSN (Online): 2319-7064 \\ Index Copernicus Value (2013): 6.14 | Impact Factor (2014): 5.611}

\subsection{GC-MS instrument configuration}

Characterization of different pesticides residue were injected to GC Ms spectroscopy and the analytical spectra were done by an Agilent Technologies $6890 \mathrm{GC}$, coupled to an Agilent Technologies 5975 Quadrupole. Mass Selective Detector was used for analysis using, a $30 \mathrm{~m} \times 0.25 \mathrm{~mm} \times 0.25 \mathrm{~lm} \mathrm{DB}-5$ MS column with stationary phase 5\% vinyl and 95\% di methylpolysiloxane. The GC-MS system utilised a 5 with an injector temperature of $25{ }^{\circ} \mathrm{C}$ and a Gerstel auto sampler delivering $2 \mu \mathrm{L}$ L injection volumes at an injection speed of $50 \mu \mathrm{L} \mathrm{s}^{-1}$ and splitless mode with a purge valve time of $50 \mathrm{~s}$. Total runtime for the analysis was $37.32 \mathrm{~min}$ with initial temperature of $50{ }^{\circ} \mathrm{C}$ and hold time of $2 \mathrm{~min}$. and ramp 1 at $25{ }^{0} \mathrm{C} \mathrm{min}^{-1}$ to $160{ }^{0} \mathrm{C}$, with no hold time, followed by ramp 2 at $3{ }^{0} \mathrm{C} \mathrm{min}{ }^{-1}$ with no hold time and ramp 3 at $8{ }^{0} \mathrm{C} \mathrm{min}^{-1}$ to $270{ }^{0} \mathrm{C}$ with no hold time with a solvent delay of $4.5 \mathrm{~min}$. A constant pressure of $135 \mathrm{kPa}$ was maintained with an average linear velocity of $50 \mathrm{~cm} \mathrm{~s}^{-1}$.

\section{Results and Discussions}

\subsection{Statistical Evaluation of the Results (Repeatability)}

There are many factors that affect the ability of results including: poor instrument quality, instruments out of calibration, inadequate methods of data collection and operator inefficiency or inexperience. Hence, was carried on a repeatability test, for better results correlations

Table 2: Instrument repeatability using pesticide residue standard mixture $(0.05 \mathrm{mg} / \mathrm{L})$

\begin{tabular}{|c|c|c|c|}
\hline \multirow{2}{*}{ Compound name } & \multicolumn{3}{|c|}{ Repeatability of Peaks area } \\
\cline { 2 - 4 } & $1^{\text {rd }}$ injection & $2^{\text {rd }}$ injection & $2^{\text {rd }}$ injection \\
\hline HCH-alpha & 62700 & 63702 & 61968 \\
\hline HCH-Beta & 79470 & 78146 & 79532 \\
\hline HCH-gamma & 16728 & 17505 & 16698 \\
\hline & 19726 & 18910 & 19112 \\
\hline Heptachlor & & & \\
\hline Aldrin & 3608 & 3492 & 3303 \\
\hline Heptachlorepoxide & 10028 & 10793 & 10167 \\
\hline 2,4 DDE & 3608 & 3492 & 3303 \\
\hline Endsulphane - alpha & 9707 & 9371 & 9338 \\
\hline di-aldrin & 3785 & 3479 & 3573 \\
\hline 2,4 DDD & 7377 & 7638 & 7787 \\
\hline Endrin & 22456 & 22608 & 21717 \\
\hline Endsulphane-beta & 1522 & 1569 & 1661 \\
\hline 4,4 DDD & 6223 & 6133 & 5861 \\
\hline 2,4 DDT & 52057 & 50101 & 48893 \\
\hline 4,4 DDT & 24850 & 24207 & 24356 \\
\hline HCH-alpha & 14285 & 15234 & 15142 \\
\hline
\end{tabular}

When conducting repeated measurements for collecting data such as in this study, shrinkage of the correlation coefficients inevitably occurs. In this study, the use of multiple regression models was avoided and a classical linear regression was used for all organochlorine compounds. Shrinkage can be defined as the decrease in correlation coefficients of a calibration obtained from one data set compared to correlation coefficients of other data sets. To test the instrument repeatability, it was injected three times the standard mixture pesticide residue $(0.05 \mathrm{mg} / \mathrm{L})$. Table 3 .
Instrument repeatability using pesticide residue standard mixture $(0.05 \mathrm{mg} / \mathrm{L})$. The achieved peak areas from the successive GCMS measurements show a close repeatability of the results, under same instrumental analysis conditions.

Moreover, results for real mean peak area, standard deviation of peak areas and relative standard deviation (RSD \%), from injected standard mixture. 0.04 p.p.m. presented in table 2 .

Table 3: Calculated results for each compound using standard mixture (0.04 p.p.m)

\begin{tabular}{|c|c|c|c|c|}
\hline Compound name & $\begin{array}{c}\text { Real } \\
\text { mean } \\
\text { peak } \\
\text { area }\end{array}$ & $\begin{array}{c}\text { Stand. } \\
\text { Dev. of } \\
\text { peak } \\
\text { areas }\end{array}$ & $\begin{array}{c}\text { RSD } \\
\%\end{array}$ & $\begin{array}{c}\mathrm{t}^{-d i s t r i b u t i o n} \\
\left(\mathrm{t}_{, 0.95}\right)\end{array}$ \\
\hline HCH-alpha & 62790 & 870 & 1.39 & 4.30 \\
\hline HCH-Beta & 49049 & 783 & 0.99 & 4.28 \\
\hline HCH-gamma & 16977 & 458 & 2.69 & 4.30 \\
\hline Heptachlor & 19249 & 425 & 2.21 & 4.30 \\
\hline Aldrin & 6191 & 108 & 1.74 & 4.30 \\
\hline Heptachlorepoxide & 10329 & 408 & 3.95 & 3.27 \\
\hline 2,4 DDE & 3467 & 154 & 4.44 & 4.30 \\
\hline Endsulphane - alpha & 9472 & 204 & 2.16 & 4.31 \\
\hline di-aldrin & 3612 & 157 & 4.34 & 4.30 \\
\hline 2,4 DDD & 7600 & 207 & 2.73 & 4.30 \\
\hline Endrin & 22260 & 476 & 2.14 & 4.30 \\
\hline Endsulphane-beta & 1584 & 78 & 4.46 & 4.30 \\
\hline 4,4 DDD & 6072 & 188 & 3.10 & 4.30 \\
\hline 2,4 DDT & 50350 & 1596 & 3.17 & 4.30 \\
\hline 4,4 DDT & 2447 & 336 & 1.38 & 4.30 \\
\hline HCH-alpha & 14887 & 523 & 3.52 & 4.30 \\
\hline
\end{tabular}

\subsection{Instrument detection limit}

The instrument detection limit is the lowest detection above equipment, electronic signal noise. To set the lower detection limit, different concentrations of standard mixtures injected to GC-MS $(0.08,0.06,0.04,0.02,0.01$, and 0.005) p.p.m.

Figure 1, represents an example of an appropriate correlation between peak intensities, using different concentrations of pesticide residue standard mixtures.

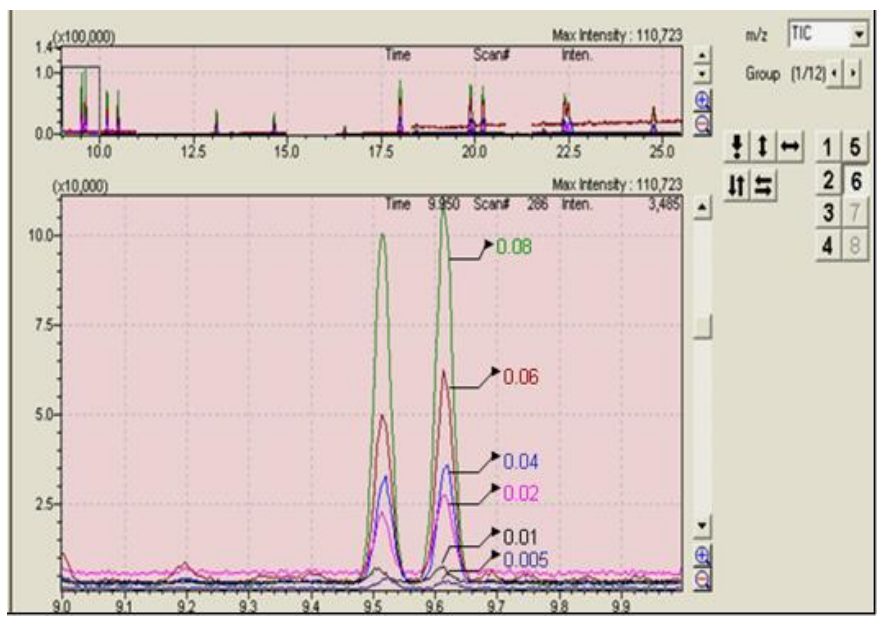

Figure 1: Peak intensities using different concentrations of pesticide residue standard mixtures. 


\section{International Journal of Science and Research (IJSR) \\ ISSN (Online): 2319-7064}

Index Copernicus Value (2013): 6.14 | Impact Factor (2014): 5.611

\subsection{Limit of Quantitation (LoQ)}

Limit of quantitation (LoQ) is the lowest analyte concentration of spiked samples. In this validation study LoQ was performed on two examples and evaluated by multiplying with 5 calculated the standard deviation of the compound plus a concentration of lowest peak area of the blank. Recovery sample with spiked amount 0.05 p.p.m and other second recovery sample spiked 0.02 p.p.m, both results presented in table (4). The fraction of analyte added to a test sample (fortified or spiked sample) prior to analysis and percent recovery $(\% \mathrm{R})$ is computed as follows:

$$
\mathrm{R}(\%)=[(\mathrm{CF}-\mathrm{CU}) / \mathrm{CA}] \times 100
$$

$\mathrm{CF}$ is the concentration of analyte measured in the spiked sample. $\mathrm{CU}$ is the concentration of analyte measured in the unfortified sample while, CA is the concentration of analyte added (measured value) in fortified sample.

The LoD and LoQ were calculated as follows:

Limit of detection $(\mathrm{LoD})=$ average concentration $+3 \mathrm{SD}$ Limit of quantitation $(\mathrm{LoQ})=$ average concentration $+5 \mathrm{SD}$

Table 4: Limit of quantitation for organochlorine pesticides (spiked amount 0.05 p.p.m, and 0.02 p.p.m)

\begin{tabular}{|c|c|c|}
\hline Compound name & $\begin{array}{c}\text { LoQ } \\
(0.05 \text { p.p..m })\end{array}$ & $\begin{array}{c}\text { LoQ } \\
(0.02 \text { p.p.m })\end{array}$ \\
\hline HCH-alpha & 0.012 & 0.021 \\
\hline HCH-Beta & 0.012 & 0.015 \\
\hline HCH-gamma & 0.012 & 0.023 \\
\hline Heptachlor & 0.016 & 0.021 \\
\hline Aldrin & 0.011 & 0.014 \\
\hline Heptachlorepoxide & 0.011 & 0.03 \\
\hline 2,4 DDE & 0.023 & 0.01 \\
\hline Endsulphane - alpha & 0.036 & 0.025 \\
\hline di-aldrin & 0.026 & 0.014 \\
\hline 2,4 DDD & 0.019 & 0.023 \\
\hline Endrin & 0.022 & 0.025 \\
\hline Endsulphane-beta & 0.048 & 0.03 \\
\hline 4,4 DDD & 0.046 & 0.023 \\
\hline 2,4 DDT & 0.03 & 0.017 \\
\hline 4,4 DDT & 0.024 & 0.012 \\
\hline HCH-alpha & 0.026 & 0.03 \\
\hline
\end{tabular}

\section{Conclusions}

The instrument method calibration generating good results using standard mixture solutions over different samples concentrations. The Lower limit of detection (LoQ: 0.02 p.p.m and 0.05 p.p.m) was acceptable for all organochlorine pesticides. Moreover, the relative standard deviation (RSD\%) is reported and ranges between 0.99 for $\mathrm{HCB}$ and the highest was for 4,4 DDT.

Previously, the obtained quality control results confirmed instrument method's performance in term of the instrument accuracy, excellent sensitivity and selectivity of the consequences.

\section{References}

[1] Deng, Ji,J., . Zhang., C, H. Wu, Y. Zhang. "Microwaveassisted steam distillation for the determination of organochlorine pesticides and pyrethroids in Chinese teas," Talanta, Vol. 71, No. 3, pp.1068-1074, 2007.

[2] Meloun, M., Militky, J., Kupka, K., Brereton, R.G., "The effect of influential data, model and method on the precision of univariate calibration," Talanta, Vol. 57, No. 4, pp. 721-740, 2002.

[3] Oritz, M.C., Sarabia, L., "Quantitative determination in chromatographic analysis based on n-way calibration strategies," J. Chromatogr. A, Vol. 1158, No.1- 2, pp. 94-110, 2007.

[4] Pell, R.J., "Multiple outlier detection for multivariate calibration using robust statistical techniques," Chemom. Intell. Lab. Syst. Vol. 52, No.1, pp. 87-104, 2000.

[5] Porazzi, E. Pardo Martinez, M. Fanelli, R.; Benfenati, E. "GC-MS analysis of dichlobenil and its metabolites in groundwater," Talanta, Vol. 68. No.1, pp. 146-154, 2005.

[6] Rissato, S. R. Galhiane, M. S.; Ximenes, V. F., de Andrade, R.;Talamoni, J. L. B.; Lib. nio, M.; De Almeida, M. V.; Apon, B. M.;Cavalari, A. A. "Organochlorine pesticides and polychlorinated biphenyl in soil and water samples in the northeastern part of Sã o Paulo State,” Brazil. Chemosphere, Vol. 65, No. 11, pp. 1949-1958, 2006.

[7] Tanabe, S. Iwata, H. Tatsukawa, R. "Global contamination by persistent organochlorines and their ecotoxicological impact on marine mammals," Sci. Total Environ., Vol. 154, No.2, pp. 163-177, 1994.

[8] United Nations Environment Program (UNEP). Stockholm Convention on Persistent Organic Pollutants; available online at http://www.pops.int/documents/convtext/convtext_en.pd f, Nov16, 2001.

[9] Vanatta, L.E., Cloeman, D.E., "Calibration, Uncertainty and recovery in the chromatographic sciences,". J. Chromatogr. A, Vol. 1158, No.1- 2, pp.1158, 47-60, 2007.

[10] Wania, F. Mackay, D. Peer, "Tracking the distribution of persistent organic pollutants,". Environ. Sci. Technol. Vol., 30, No 9, pp. 390-396, 1996.

[11]Zhou, Q., Xiao, J. Wang, W. Liu, G. Shi, Q. Wang, J. "Determination of atrazine and simazine in environmental water samples using multiwalled carbon nanotubes as the adsorbents for preconcentration prior to high performance liquid chromatography with diode array detector," Talanta, Vol. 68, No 4, pp. 1309-1315. 2006. 